\title{
RITMO \& REBELDIA EM JOGO: SÓ NA LUTA DA CAPOEIRA SE CANTA E DANÇA?
}

\section{MS. MARCELO BACKES NAVARRO STOTZ}

Mestre em Educação Física pelo Centro de Desportos da Universidade Federal de Santa Catarina (CDS/UFSC), Professor de Educação Física da Rede Municipal de Ensino de Brusque (PMB/SC)

(Brusque - Santa Catarina - Brasil)

E-mail: kblera@terra.com.br

\section{DR. JOSÉ LUIZ CIRQUEIRA FALCÃO}

Professor Adjunto IV da Universidade Federal de Goiás (UFG), Doutorado em Educação na Universidade Federal da Bahia (UFBA). Laboratório Physis de Pesquisa em Educação Física, Sociedade e Natureza (Labphysis/FEF/UFG) (Goiânia - Goiás - Brasil)

E-mail: joseluizfalcao@hotmail.com

\section{RESUMO}

Este estudo tem por objetivo investigar se existem e quais são as lutas e as artes marciais praticadas ao som de músicas, e apontar as semelhanças no campo das gestualidades entre estas práticas e a capoeira. Por meio de uma pesquisa bibliográfica e análises de imagens e vídeos, foram levantados elementos afins que apontam para a existência de traços semelhantes entre algumas manifestações combativas, especialmente as geradas na diáspora africana durante a escravidão, e a capoeira.

PALAVRAS-CHAVE: Capoeira; luta; artes marciais; música. 
Alguns escritores brasileiros nacionalistas do passado, cujo ufanismo continua influenciando trabalhos recentes, apresentam a capoeira como prática corporal singular do Brasil que não encontra semelhante em nenhum lugar do mundo. Esta exclusividade teria seu distintivo maior no uso da música para o acompanhamento da luta (AREIAS, 1984; CARNEIRO, 1975; COSTA, 1961).

Em diferentes indicadores e fontes como sites, livros, folders, vídeos e até trabalhos acadêmicos, pode-se encontrar a afirmação de que a capoeira é a única luta cuja prática está associada com a música e que se beneficia da aparência de dança para enfrentar o afã de seus opressores.

A pesquisa em tela demonstra que, desde os primórdios da humanidade, a música e a dança estão ligadas a muitas lutas que combinam aspectos de combate com elementos estéticos, com propósitos sociais e religiosos, mantendo conexões com ritos de fertilidade, adoração ancestral e convicções animistas.

Semelhante ao que aconteceu com a capoeira no Brasil, após o fim da escravidão, comunidades negras no Caribe e em algumas regiões da África continuaram a aperfeiçoar as técnicas remanescentes de lutas africanas, refinando seus gestos, passando a praticá-las sob a forma de jogo amistoso, onde o acompanhamento musical sempre teve papel fundamental. A aproximação com a dança, manifestada na plasticidade dos movimentos utilizados durante essas práticas, gerou uma atividade lúdica dentro da comunidade, mas que também era muito útil nas situações de confronto corporal.

Conforme será visto a seguir, em várias manifestações de luta com raízes africanas - como a Laamb, presente na região dos vales dos rios Senegal e Níger no norte da África, a Ladja e Danmyé no Caribe, e o Moringue nas Ilhas Reunião - existem evidências de elementos comuns à capoeira, em que a dança e a música se misturam com os combates.

Nessas práticas, a música constitui importante componente para resistir física e psicologicamente às diversas formas de violência. Por meio do ritmo criado por instrumentos de percussão, se desenvolve um eficaz senso de coordenação e noção de tempo (timing) no praticante, bem como deslocamentos funcionais para a esquiva e o ataque precisos (como a ginga da capoeira) que acabam escamoteando a verdadeira função dos movimentos (GREEN, 200 I).

É bem possível que a associação da música com as práticas dos guerreiros africanos tenha sido um dos principais fatores que permitiu que essas estratégias de resistência corporal lograssem êxito, já que os padrões de treinamento eram vistos apenas como "danças", ao invés de exercícios marciais. O exemplo mais conhecido 
atualmente é, sem dúvida, a capoeira, mas outras lutas, com aspectos técnicos e histórias semelhantes, já começam a ser mais divulgadas, ainda que no estrito campo dos trabalhos acadêmicos.

Ainda que a capoeira reúna características específicas que a diferenciam de outras manifestações africanas que migraram para os países onde houve a escravidão negra, parece haver muito pouco espaço para dúvidas de que existam características semelhantes entre ela e outras lutas desenvolvidas na África, nas Américas ou nas ilhas do Oceano Índico por africanos e seus descendentes.

De crime nacional a modismo internacional, uma prática associada a malandros e vagabundos, a capoeira transmutou-se em uma atividade ligada a ações sociais promovidas por educadores populares, passando inclusive de "coisa do demônio" a ser utilizada como instrumento de evangelismo. Essas transformações recentes da capoeira promoveram mudanças significativas, muitas controvérsias e mitos em seu contexto.

Instrumento formal da ideologia, o mito usado como argumento é comum nos enfrentamentos ideológicos em contextos de disputas de poder, como nas discussões sobre o maior (ou menor) grau de autenticidade deste ou daquele estilo de capoeira (SOUZA, 1983). Nesse contexto, os defensores de diferentes correntes de pensamento sempre se remetem à questão das tradições, sem levar em consideração que todas elas são inventadas, sendo que algumas bem recentemente (HOBSBAWM, 1995).

Alguns fatos históricos relativos ao passado, convenientemente recortados, são apropriados pelos capoeiristas e divulgados em relatos orais e escritos por mestres, ou sobre eles, e também em músicas cantadas durante as rodas. Sem diminuir a importância da contribuição da história oral, é preciso estar atento quando a mitologia assume exclusivamente o papel das fontes básicas para explicar a trajetória da capoeira, dando significados diferentes aos momentos históricos para justificar determinados atos como, por exemplo, a adoção de determinados recursos de ensino, a hierarquização ou mesmo atitudes de seus praticantes.

$\bigcirc$ fato é que a capoeira, como elemento marcante e representativo de um fenômeno antropológico intrinsecamente ligado a diversos episódios da história do Brasil, ainda carece de estudos e conseqüentes discussões sobre questões que possam ajudar no esclarecimento de sua complexidade. É necessário trazer à luz da ciência teorias, lendas e equívocos que continuam a povoar os discursos de expressivo número de estudiosos e praticantes da capoeira, que visam apenas a valorização e afirmação convenientes de referências simbólicas do processo civilizatório afro-brasileiro.

Sem desconsiderar a possibilidade "das musicalidades das rodas de capoeira(s) constituírem um capital simbólico, ou seja, em objeto de prestígio e de disputa por 
posições de destaque neste espaço singular, que é o universo cultural da capoeira" (CORTE REAL, 2006, p. 14), não se tem a pretensão de discutir tais melindres, mas problematizar afirmações do tipo: "a capoeira é a única luta no mundo a contemplar acompanhamento musical através de instrumentos e cânticos" (ESTEVES, 2004, p. 43).

Entre outros mitos, tal asseveração se tornou tão recorrente no meio capoeirístico, que já faz parte "do inconsciente coletivo do brasileiro, permitindo que, mesmo em estudos acadêmicos rigorosos, realmente inovadores em muitos aspectos" (VIEIRA; ASSUNÇÃO, I 998, p. 84), possam aparecer citações que acabam reforçando a ideia de que "a capoeira é conhecida como única luta no mundo em que seus lutadores se confrontam ao som de cânticos executados pelos demais componentes" (FALCÃO, 1996, p. 108). Essa ideia ainda persiste no discurso de capoeiristas, estudiosos e simpatizantes.

\section{CONSTRUINDO, ANALISANDO E PROBLEMATIZANDO FONTES NÃO CONVENCIONAIS}

Para responder aos objetivos propostos e incrementar as análises, além do uso de fontes bibliográficas convencionais fundamentadas na pesquisa bibliográfica e documental com abordagem qualitativa, por meio de fontes primárias e secundárias, recorreu-se à utilização de documentos em hipermídia, sintonizando a pesquisa acadêmica com as transformações contemporâneas do campo científico.

As constantes evoluções na tecnologia da comunicação determinam a necessidade de criar novos mecanismos de tratamento da informação (LADNER, 1996), aonde a internet vem tornando-se gradativamente a mais importante ferramenta de pesquisa nas diversas áreas de conhecimento (CLAUSEN, 1997).

Dentre outros materiais, foram obtidos vídeos na internet, por meio da busca em endereços eletrônicos como o youtube, sobre diversas lutas, bem como documentários, trechos de reportagens televisivas e outras referências significativas, apesar de serem "construções realizadas sob a influência da sociedade em que se vive (e) se constituem em símbolos que expressam a cultura e a consciência histórica dessa mesma sociedade" (CUNHA, 2002, p. 68). Com esse material disponível, foi possível analisar os traços gestuais, simbólicos e ritualísticos de práticas inseridas na diáspora africana.

Cabe salientar que é imprescindível selecionar, criticamente, o que estes mediadores transmitem para a sociedade como real, pois são representações simbólicas sobre o mundo construídas pelo homem contemporâneo que "dizem mais do que aquilo que mostram ou enunciam, carregam sentidos ocultos, que, 
construídos social ou historicamente, se internalizam no inconsciente coletivo" (PESAVENTO, 2005, p. 4I).

Por meio de tais produções, foi possível obter virtualmente registros fílmicos fidedignos de manifestações de culturas distantes que há pouco tempo só eram vistas ou conhecidas através de uma pesquisa de campo in locus. Ademais, a maioria dos programas de pós-graduação no Brasil não conta com recursos para o custeio de viagens para um trabalho de campo aprofundado.

Além disso, as tecnologias emergentes aplicadas à informação e educação, com base no armazenamento, recuperação e comunicação de informação de modo mais amplo (LÉVY, 1993), têm alterado as limitações dos processos comunicacionais e contribuído sobremaneira para a flexibilidade, desterritorialização e rapidez do processo de informação, que beneficia pesquisadores, representando recurso vital de instrumentalização para a pesquisa acadêmica.

\section{NEM SÓ NA LUTA DA CAPOEIRA SE CANTA E DANÇA!}

De um modo geral, assim como a capoeira, as artes marciais surgiram como ferramenta para as lutas sociais. Seus praticantes precisavam desenvolver estratégias coletivas de resistência cultural e de luta social em favor de seus interesses. As lutas expressavam, portanto, o modus operandi do contexto onde foram criadas, e funcionavam como uma espécie de "espelho" dos movimentos sociais, em que cada grupo transmitia às novas gerações, filosofias próprias.

A música, incorporada às lutas, também servia como veículo para a transmissão destas visões de mundo. Isso ocorre no Penjack Silat indonésio, no Kali filipino, no Muay Thai da Tailândia, para citar apenas as lutas mais conhecidas. No entanto, existem muitas outras lutas onde a música tem um papel fundamental.

Podemos ver a seguir algumas artes guerreiras de origem africana em que a luta, a dança e a música se misturam em rituais temperados de componentes lúdicos, mágicos e religiosos.

Entre as lutas africanas de corpo a corpo (wrestling)', talvez a mais popular seja a Laamb, palavra do wolof que se traduz por "luta" (DESCH OBI, 2008, p. 82). Pode ser encontrada em países como Benin, Nigéria, Costa de Marfim, Togo, Gana, Burkina e Mali.

Cada luta dura apenas alguns minutos, mas é precedida por horas de preparação física e espiritual, fanfarra e música. Há duas formas de Laamb: uma permite

I. Wrestling é uma designação genérica para combates em que predominam os agarrões e os desvencilhamentos. 
aos lutadores golpear um ao outro com as mãos nuas; a outra é mais acrobática, e não é permitido bater. Em ambos os estilos, o vencedor tem que conseguir fazer com que o oponente caia com os joelhos, ombros, ou as costas no chão.

Os praticantes têm seus treinadores, são organizados em equipes (muito semelhante ao Sumô do Japão), e viajam pelas aldeias para desafiar novos lutadores. Normalmente são da etnia Wolof e Mandinga, povo de religãa predominantemente maometana, que vive na parte norte da África ocidental, nos vales dos rios Senegal e Níger.

Cada lutador de Laamb tem seu próprio grupo de tocadores de tambor e fala freqüentemente com eles. Na noite anterior às competições, os bateristas constroem tambores novos e dentro deles colocam proteções, talismãs pessoais do lutador. Também passam a noite na casa do lutador para que ele não faça sexo. Nenhum lutador ousa entrar no ringue sem o seu "marabout" (feiticeiro) ou sem participar da cerimônia preparatória.

As lutas acontecem freqüentemente durante a noite ou à tarde no centro das aldeias, os competidores comparecem vestidos com a tanga tradicional (guimbe) dos lutadores africanos, constituída por "envolturas" ao redor da cintura, providas pelas noivas ou parentes femininos. A multidão se reúne ao redor de uma cova arenosa e todos cantam, dançam e contam histórias de um passado glorioso, embalados pela batida dos tambores e a voz dos cantadores (MENESES, 2009).

Os tambores anunciam a preparação mística (Baccou) que antecede o começo da luta. A fala do "griot"2 encoraja os lutadores (LEYMARIE, 1999, p. 7I), dando ritmo às danças e anunciando cada competidor, que dança ao redor da arena para impressionar os adversários. O ritmo é chamado Barambaye, e só os homens dançam para mostrar sua força para os outros lutadores. As mulheres adultas dançam (Ndawrabine) durante as lutas.

A competição entre os tocadores de tambor (sabar), que representam cada um dos competidores (LUTTE LAMB SENEGAL BAKOU BALLA GAYE), é quase tão importante quanto a que acontece entre os lutadores. Os tocadores de tambor pertencem à casta dos "griots", homens que encarnam a cultura do seu povo em si próprios, e que têm a tarefa de mostrar as contribuições de cada grupo familiar para o progresso da sociedade, geração por geração. Também chamado de Djeli, cada griot é um historiador, músico, dançarino e artista, que ensina crianças e adultos, e é freqüentemente um conselheiro no tribunal real (HENRICH, 200I).

2. Na África, os griots são considerados os profissionais da oratória, e são conhecidos como contadores de histórias, que sabem de memória os saberes, as crenças, as lendas, os costumes dos seus povos e repassam de geração a geração. São também poetas e músicos. Para saber mais consultar Leymarie (1999) e Luz (2000). 
Enquanto o griot faz seu elogio, dançando o lutador chega mais perto dos músicos com gestos rápidos e aos arrancos. Pedindo emprestada a fala ao griot, o lutador canta sua força e invencibilidade recitando os poemas de luta chamados "bakks", um tipo de canto de improviso para encorajar os atletas. A multidão aplaude a cada performance (LEYMARIE, 1999, p. 69). Os tocadores de tambor até 1980 eram exclusivamente masculinos, pois há tabus contra mulheres tocando tambor. Porém, hoje já existem algumas bateristas femininas no Senegal. Todos aprendem a tocar tambor com os pais, de maneira informal.

Atualmente, Laamb está se tornando popular também nos EUA, onde há uma grande comunidade imigrante senegalesa, porém estão se incluindo elementos estrangeiros para ajustar essa prática corporal aos gostos ocidentais. As lutas são patrocinadas, e são pagos prêmios em dinheiro (GREEN, 200I).

Outra luta em que a musicalidade e a dança fazem parte do ritual é a Kadja, praticada ao som de tambores e flautas pelo povo bassantché, no norte de Benim, durante as festas rituais ligadas às celebrações da colheita do inhame. Esta manifestação guerreira é apontada como uma provável origem da Ladja na Martinica, um jogo corporal que guarda semelhanças com a capoeira (VIEIRA, 2002). A coincidência na sonoridade dos nomes é, no mínimo, um indicativo desta possibilidade, porém a Kadja se aproxima também do wrestling, incorporando um vasto leque de técnicas para ser usado quando um guerreiro perde suas armas (GREEN, 200I).

O N'golo, que para alguns pesquisadores constitui num ancestral da Ladja caribenha, é outra prática corporal que mistura luta, dança e música. Na língua kikongo, falada em algumas regiões de Angola, a palavra n'golo significa força ou poder, mas o termo também faz referência à zebra e a maneira daquele animal lutar. Os gestos da zebra eram reproduzidos pelos jovens dos grupos mucupes e mulondo, na região do atual sul de Angola, durante as festas dos rituais de puberdade das moças, quando os homens se enfrentavam no centro de um círculo formado por cantores e possíveis combatentes, que animavam a competição (SOARES, 1999).

Segundo o pesquisador americano Desch Obi (2008), as lutas de N'golo eram precedidas por combates em que os adversários se enfrentavam com golpes de mãos abertas, a kandeka (também conhecida como liveta). Em ambas as lutas, enquanto lutadores se revezavam individualmente no interior de um grande círculo, um círculo exterior de membros da comunidade ajudava os competidores a manter um ritmo constante, batendo palmas e entoando canções de chamada e resposta, em que todos os presentes respondiam o coro (ASSUNÇÃO, 2005).

Depois que a música tomava conta da multidão, um lutador entrava no círculo e levantava as mãos abertas acima da cabeça, como um desafio a todos os presentes. Outro lutador, geralmente aquele que se sentia próximo ou acima do 
nível de habilidade do adversário, entrava no círculo com passos dança e levantava as mãos abertas, palmas para frente, aceitando o desafio (DESCH OBI, 2008).

Em Angola existe também uma dança chamada umudinhu, praticada exclusivamente pelos quilenge ao som de palmas e cantos. Esta dança foi testemunhada pelo etnógrafo português Augusto Bastos no início do século XX (ASSUNÇÃO, 2005).

Algumas lutas que se utilizam de músicas e danças também podem ser encontradas no Oceano Índico. "As mais importantes nesta região são Mrengé (Comores), Morengy (Madagáscar), e Moringue (Illhas Reunião). Como os nomes semelhantes sugerem, estes três jogos de combate estão intimamente relacionados (ASSUNÇÃO, 2005, p. 54).

O Mrengé de Mayotte, praticado pelas classes trabalhadoras, é fortemente enraizado nas tradições da ilha. Como o Moraingy do norte de Madagáscar, os praticantes usam os punhos nus e lutam ao som de dois ou três Ngoma, tambores que dão o ritmo da batalha. Os tambores são acompanhados por um objeto transformado em instrumento de percussão, que produz um som metálico. O Ngoma é um tambor tradicional feito no tronco de uma árvore, que pode ser tocado de pé ou no chão, entre as pernas do percussionista. Nos Comores este instrumento é tocado por homens, mulheres e crianças que, por meio da música, enviam mensagens de encorajamento para apoiar os combatentes.

Assim como acontece em Reunião e Madagáscar, os lutadores e o público fazem um círculo em torno dos bateristas. As ações preliminares da batalha podem durar vários minutos, período em que os músicos aquecem a multidão com o ritmo binário da percussão. Os lutadores, cruzando várias vezes o espaço circular e brandindo o punho para cima ou horizontalmente, convidam um rival a surgir. Após um tempo, um lutador acaba aceitando o desafio, e a luta acontece sob o controle de um ou dois árbitros para garantir condições justas e não descambar em uma briga selvagem. Quando a violência é extrema e os lutadores não querem parar, a platéia intervém para ajudar os árbitros e parar a luta.

Assim como outras formas de combate associadas ao uso de um acompanhamento musical, o Mrengé despertou o interesse de alguns estudiosos, como o professor Edward L. Powe. Referência constante nos diversos trabalhos que investigam as lutas e jogos de combate resultantes da diáspora africana no período escravista, Powe disponibilizou na internet os textos de sua autoria que fazem parte de um conjunto de obras denominado "Black Martial Arts Series". Em sua home page (The Black Languages, Arts, \& Culture Foundation), é possível encontrar um capítulo do livro Combat Games of the African Indian Ocean, dedicado ao "The Mrengé Combat Dance Tradition of Moheli” (POWE, 200 I), de onde foram extraídas as informações que se seguem. 
Powe (200 I) afirma que a tradição dos jogos de combate, acompanhados por canções peculiares, aparece em todo o arquipélago, mas prospera com mais vigor no sudeste da Grande Comore, na ilha de Moheli, nas aldeias de Fomboni, Ziroudani, Wanani e Nioumachoua, onde se encontra uma tradição chamada mrengé ntsi (Mrengé), possivelmente originada em Moçambique e difundida na diáspora africana para Comores.

Por meio de entrevistas com praticantes mais experientes, Powe (200l) verificou que, em tempos remotos, a orquestra que acompanhava a luta era composta exclusivamente por tambores e uma flauta de três furos (ndjumari), mas hoje seu uso foi abandonado. Atualmente são usados com mais freqüência os seguintes instrumentos: Dori, um tambor pequeno apoiado em torno da cintura, que é percutido com uma mão e uma vara para produzir um som agudo; fuba, um tambor grande, também batido com uma mão e um pedaço de pau; shingangwa, um tambor médio colocado no chão e percutido com duas varas; gadza, duas placas fechadas de fibra com grãos dentro; e garando, um instrumento parecido com um balde, que é batido com varas de madeira. Alguns músicos têm inovado incluindo outros instrumentos, como o kabosy, um instrumento de cordas semelhante a um cavaquinho, e outros mais modernos introduzidos a partir de França, como guitarras e até mesmo sintetizadores.

Em seu livro, Powe (200 I) descreve um evento acontecido no dia I 3 de outubro de 1999 na cidade de Nioumachoua, e transcreve algumas canções tradicionais utilizadas para animar as lutas de Mrénge. Algumas dessas músicas possuem uma estrutura semelhante aos "corridos" 3 cantados nas rodas de capoeira, onde o refrão é cantado após cada verso de duas linhas. Assim como na capoeira, as canções têm diversas funções, como conservar as tradições locais e perpetuar a memória daquela população.

Muitas vezes os ânimos são alterados quando os cantores zombam ou provocam alguém, por meio das "músicas do ridículo", algo semelhante às cantigas de escárnio e de mal dizer utilizadas na capoeira (REGO, 1968, p. 235-240). Este mesmo uso das cantigas ocorre em outras práticas, como Dambe do norte da Nigéria, Ladja da Martinica e Kalenda de Trinidad. Uma possível razão para tais canções é fazer com que as emoções levem a uma disposição apropriada para a luta.

Segundo Powe (200I), as lutas são precedidas por danças em que os lutadores desafiam seus opositores. Os adversários iniciam o confronto ficando

3. Em geral, as cantigas na capoeira são classificadas em ladainhas, chulas e corridos. Os cantos corridos, por sua vez, constituem-se em cantos rápidos, geralmente de um ou dois versos, em que o coro repete ou responde as cantigas do puxador. 
de cócoras no centro do círculo, frente a frente, e então passam a empregar várias técnicas e estratégias visando colocar o concorrente fora de combate. Pode-se bater no adversário em qualquer lugar. Vale chutar, morder, jogar areia e cuspir. Entre adultos é considerado lícito o uso de alguns subterfúgios, como lançar areia nos olhos do adversário ou atacá-lo pelas costas, mas é considerado desleal usar qualquer coisa além de seu corpo para vencer.

Dentre as práticas citadas por Powe (200 I), chama atenção o Moringue das Ilhas Reunião, no Oceano Índico. Essa luta se utiliza de movimentos extremamente semelhantes aos da capoeira, como aús, armadas, chapas e pisões, rabos de arraia, meia luas de frente, queixadas etc ${ }^{4}$. No entanto, não existe a ginga: a preparação para o golpe se dá com um gestual mais próximo ao do nosso samba duro ou do Batuque, com uma movimentação que lembra o Maculelê, ou até mesmo o Frevo (MORINGUE AU THÉÂTRE SOUS LES ARBRES MAI, 2008).

A movimentação do Moringue também se parece muito com o jogo de Samango (AULA DO MESTRE CANJIQUINHA, 2006), uma invenção do mestre Canjiquinha, que também criou um toque específico de berimbau para acompanhar o jogo (CORTE REAL, 2006). Quanto à ritualização do Moringue, aparentemente lembra mais o Batuque ou a Punga do Maranhão (PUNGA MARANHENSE, 2007) do que uma roda de capoeira (MORINGUE, 2008).

O historiador Sudel Fuma, especialista da parte africana da ilha na Universidade das Ilhas Reunião bem como membro do "Espace Afrique", uma associação que milita em prol da revalorização da África na ilha, é autor de diversas obras relacionadas com o tema da escravidão. Para Fuma (1992), antes da proclamação oficial da abolição da escravidão em 1848, o Moringue era considerado como o lazer exclusivo dos Kaf (nome crioule dado aos negros da Reunião), e por isso visto como uma atividade degradante para a sociedade colonial. Até 1848 , somente os negros praticavam a luta, no meio das plantações de cana-de-açúcar e café, pois o ritual incomodava seus senhores. Nenhum branco e nem sequer o creole (criolo) a praticavam.

A partir do início do século XX, o Moringue adquiriu um caráter mágico, que atraiu também os "crioulos de cor" de origem africana e os "pequenos brancos". Toda a população passou a praticá-la como cultura "cafre" (pertencente ao crioule) por excelência, reagrupando músicas e danças inicialmente ligadas à religião e à cultura dos marrons (escravos que escapavam das plantações).

4. Com algumas variações de região para região, os nomes dos golpes de capoeira são disseminados em língua portuguesa e reproduzidos entre praticantes dessa manifestação ao redor do mundo. Os golpes citados acima são comuns e conhecidos em várias partes do mundo sem maiores variações. Não há espaço para fazer uma descrição pormenorizada de cada um deles nesse texto. Para saber mais ver, entre outros, Rego (1968). 
Até Primeira Guerra Mundial, as lutas de moringue eram a principal atividade de lazer das Ilhas Reunião e seus rituais de magia tinham um papel importante na vida da população, permitindo livrar, momentaneamente, a mente do corpo torturado pelos problemas sociais diários acumulados, servindo como um modo de transferência e expulsão das pressões de uma ordem social traumática e rígida.

Em 1946, essa colônia francesa do Oceano Índico se tornou um departamento ultramarino da França, e o estilo de vida local passou a sofrer mudanças profundas. O passado colonial e a escravidão foram negados em uma surpreendente perda coletiva de memória, incluindo o Moringue, substituído por outras atividades de lazer que não tinham a mesma significação cultural.

A dança-luta esteve proibida até os anos 1960 pelo governo francês, quase desapareceu no final dos anos 1980 e renasceu, em grande parte, graças a Jean René Dreinaza (campeão europeu de Boxe-Francês), que trabalhou durante anos para o reconhecimento e o desenvolvimento desta manifestação cultural, alegre e tradicional. Depois de anos de busca minuciosa, em 1989, Dreinaza e outros pesquisadores, como o historiador Sudel Fuma, conseguiram recuperar rastros das origens do Moringue, especialmente em Madagáscar.

A descrição dos gestos, as passagens e rituais transmitidos de pai para filho pela tradição oral, foram permitindo aos pesquisadores recuperar algumas características das formas de expressão corporal dos ex-escravos. Porém, a arte não renasceu com suas formas idênticas aos tempos coloniais, perdendo um pouco de sua autenticidade de origem, e hoje é mais similar à capoeira do Brasil do que ao Moringue tradicional de Madagáscar ou Comores (FUMA, 2006).

É possível que o sucesso da internacionalização da capoeira tenha contribuído para a descaracterização do Moringue, porém esta influência parece ter interferido também positivamente para o seu ressurgimento. Talvez um passo importante nesse processo tenha se dado com a visita de um pequeno grupo de mestres de capoeira à llha de Reunião em outubro de 1984, para participar do Festival de Temoignages. Entre outros objetivos, os promotores da viagem tinham a intenção de revitalizar essa prática corporal muito semelhante à capoeira.

A partir do esforço de seus praticantes, e com o apoio governamental, o Moringue passou a ser tratado como esporte, cultura e espetáculo de povo das Ilhas Reunião, sendo reconhecido como esporte pelo "Ministère de la Jeunesse et des Sports" em 13 de setembro de 1996, quando se criou a Federação Francesa de Moringue.

Durante os intervalos das lutas, o espectador pode assistir apresentações que podem ser animadas com Maloya, misto de música e dança tradicional das llhas Reunião, cultura "dos pretos" da África e da llha de Madagascar, levada pelos negros 
que foram escravizados para trabalhar nas plantações na época colonial. A música é semelhante à utilizada para animar os combates de Moringue. Caracteriza-se por uma alternação de palavras entre o solista e o coro, que prolongam a oração do cantor ou as respostas a ele. Foi proibida até o começo dos anos 1980, por causa de seu poder de "juntar as multidões".

O Moringue esportivizado ainda busca seu espaço, mas não há dúvidas que, em sua forma popular de um jogo, já não corre mais o risco de desaparecer. Em ambas as formas, o combate é animado por um grupo de músicos que cantam e batem tambores de procedência afro-malgache. "Le tambour" (o tambor) é um termo genérico que designa uma seção constituída por cinco percussionistas, onde um tambor principal dirige a seção musical inteira, regulando o progresso da luta. Alma ressonante da atividade, o tambor controla o combate, fazendo as variações necessárias para modular a intensidade da luta de acordo com fases técnicas precisas, e de acordo com a idade do moringuer.

A seção musical mais comum inclui três djembés: baixo, médio e contralto, que executam funções semelhantes ao trio de berimbaus da orquestra da Capoeira Angola. Assim como o berimbau mais grave (gunga ou berra boi) na Capoeira, o último djembé, o contralto, é o instrumento principal que acompanha e orienta os lutadores no caso de desrespeito das regras técnicas (descontrole dos golpes, desproporções de força entre dois lutadores, situações de risco etc.), e na ausência de árbitro.

Os djembés alternam acompanhamentos, variações e solos; os doums-doums (tambores horizontais de duas peles) mantêm a marcação de um modo cíclico, sendo o couro batido com uma vara segura numa das mãos, enquanto a outra manipula um sino metálico; o pikèr completa o acompanhamento: um pedaço de bambu é percutido com duas varas em vários lugares, produzindo diferentes sons.

Em sua forma popular, o combate acontece dentro de uma roda formada pelos assistentes, e existe todo um ritual antes da confrontação para provar a superioridade de um time ou de um indivíduo sobre outro. $\bigcirc$ ritual começa com uma festa regada a música e rum, onde todos se divertem e acertam as lutas. $\bigcirc$ rum dá coragem aos lutadores e excita os partidários. Antes de lutar, os moringuers consultam um feiticeiro.

O Moringue tem diversas semelhanças com a capoeira. As técnicas acrobáticas (golpes altos com os pés, saltos, tesouras, rasteiras, paradas de mãos etc.), a própria indumentária dos lutadores (torso e pés nus, calças compridas brancas) e o uso de instrumentos de música para dar ritmo às lutas (dois djambés, um piker e um doum-doum). Os combates acontecem tradicionalmente no centro de um círculo formado pelos participantes, como numa roda de capoeira. 
O uso de apelidos também é uma tradição entre os moringuers, assim como na capoeira, onde Bimba, Besouro, Caiçara, Canjiquinha e tantos outros se tornaram mundialmente conhecidos e eternizados. Através da tradição oral e das cantorias durante o jogo, grandes lutadores que marcaram a história da ilha como "Laurent le diable", "Coco l'enfer", "Henri la flèche", "Cadine", "Chou-fleur", "La Marc Café" sobrevivem na memória dos atuais praticantes.

Os pontapés circulares são aplicados com uma mão apoiada no chão, não são permitidos socos ou agarrões, e alguns movimentos são extremamente parecidos com os de capoeira. Todos os nomes dos golpes são exclusivamente no dialeto crioule. Os moringueurs também usam calças compridas brancas, chamadas mauresque, algo comparável ao abadá utilizado na capoeira.

Todas as expressões guerreiras citadas misturam luta, dança e música, e para se adaptarem a contextos adversos, potencializaram práticas educativas extremamente complexas, em que o corpo é apropriado como um depósito do inconsciente coletivo e arcabouço de perpetuação de uma nova "linguagem" que atua como um "canal de conexão entre o sensível e o intangível" (CORTE REAL, 2006, p. 17I).

\section{CONSIDERAÇÕES FINAIS}

Conforme se pode verificar, o argumento alardeado entre pesquisadores e praticantes, de que a capoeira é a única luta no mundo praticada ao som de instrumentos musicais e cânticos, não tem confirmação científica. Esse estudo demonstrou que argumentos que afirmam "não haver, no continente africano e nos outros países influenciados pela raça negra, nada parecido com a capoeira” (SILVA, 2002, p. I I), não se sustentam cientificamente.

O desvelar de aproximações, semelhanças e contradições existentes entre a capoeira e outras manifestações combativas, especialmente as geradas na diáspora africana, veio acompanhado de subsídios teóricos e empíricos capazes de levantar questionamentos em futuras análises dessas práticas corporais que, ao que parece, até então têm sido tratadas, nos trabalhos acadêmicos, a partir de perspectivas muito focalizadas, sem considerar suas inevitáveis relações e articulações com outras práticas.

\section{Rhythm \& rebellion in play: only in fight of capoeira one can sing and dance?}

ABSTRACT: This study aims to investigate whether there are and what are the fights and the martial arts committed to the sound of music, and point out the similarities in the field of gestures between these practices and capoeira. Through a literature search and analysis of images and videos have been raised related elements that point out to the existence of 
similar traits among some militant demonstrations, especially those generated in the African diaspora during slavery, and the capoeira.

KEYWORDS: Capoeira; fight; martial arts; music.

\section{Ritmo \& rebeldía en juego: ¿sólo en la lucha de capoeira si puede cantar y bailar?}

RESUMEN: Este estudio tiene como objetivo investigar si existen y cuáles son las peleas y las artes marciales comprometidas con el sonido de la música, y señalar las similitudes en el ámbito de los gestos entre estas prácticas y la capoeira. A través de una búsqueda bibliográfica y el análisis de imágenes y vídeos se han planteado como elementos que apuntan a la existencia de rasgos similares entre algunas manifestaciones militantes, en especial los generados en la diáspora africana durante la esclavitud, y la capoeira.

PALABRAS CLAVES: Capoeira; lucha; artes marciales; música.

\section{REFERÊNCIAS}

AREIAS, A. O que é capoeira. São Paulo: Brasiliense, 1984.

ASSUNÇÃO, M. Capoeira: the history of an afro-brazilian martial art. New York: Taylor \& Francis, 2005.

AULA DO MESTRE CANJIQUINHA: capoeira (parte I). Disponível em: <http://www. youtube.com/watch?v=8vzhS-iCBAk>. Acesso em: 02 jan. 2010.

CARNEIRO, E. Capoeira. Rio de Janeiro: MEC/Funarte. I 975. (Cadernos de Folclore, I)

CLAUSEN, H. Online, cd-rom and web: is the same difference? Aslib Proceedings, London, v. 49, n. 7, p. 177-183, july/aug. 1997.

CORTE REAL, M. P. As musicalidades das rodas de capoeira(s): diálogos interculturais, campo e atuação de educadores. 2006. 346 f. Tese (Doutorado em Educação) - Centro de Ciências da Educação, Universidade Federal de Santa Catarina, Florianópolis, 2006.

CUNHA, M. F. Cantando o Brasil pós-64. História e Ensino, Londrina, v. 8, p. 67-81 , 2002.

DA COSTA, L. P. Capoeiragem: a arte da defesa pessoal brasileira. Rio de Janeiro: Selbstverl, $196 \mid$.

DESCH OBI, T. J. Fighting for honor: the history of african martial art traditions in the atlantic world. Columbia: University of South Carolina, 2008.

ESTEVES, A. P. A "capoeira" da indústria do entretenimento: corpo, acrobacia e espetáculo para "turista ver". Salvador: Bureau, 2004. 
FALCÃO, J. L. C. A escolarização da capoeira. Brasília: Royal Court, 1996.

FUMA, S. Le moring, art de combat afro-malgache: une mémoire interculturelle de l'esclavage dans les petites îles du sud-ouest de l'océan Indien occidental. In: COLLOQUE EXPÉRIENCES ET MÉMOIRE: PARTAGER EN FRANÇAIS LA DIVERSITÉ DU MONDE. Bucarest, sept. 2006. Anais... Disponível em: < http://www.celat.ulaval.ca/histoire.memoire/b2006/Fuma. pdf $>$. Acesso em: 03 jan. 2010.

Ocean, 1992.

; DREINAZA, J.-R. Le moring, art guerrier: sa pratique à la reunion. Paris:

GREEN, T. A. Martial arts of the world: an encyclopedia. New York: ABC-CLIO, 2001.

HENRICH, D. J. The griot storyteller and modern media. Communicatio, South Africa, v. 27, n. I, p. 24-27, 2001 .

HOBSBAWM. E. A era dos extremos: o breve século XX (|9|4-|99|). São Paulo: Companhia das Letras, 1995.

LADNER, S. Mutual fund information on the world wide web: part I: Issues and global resources. Business Information Review, London, v. I3, n. 2, p. 91-99, jun., 1996.

LÉVY, P. O que é o virtual? São Paulo: Ed. 34, 1993.

LEYMARIE, I. Les griots wolof du Sénégal. Paris: Maisonneuve \& Larose, 1999.

LUTTE LAMB SENEGAL BAKOU BALLA GAYE. Disponível em: < http://www.youtube. com/watch? $v=c-n b n w F u \_$_Y $>$. Acesso em: 03 jan. 2010.

LUZ, M. A. Agadá: dinâmica da civilização africano-brasileira. 2. ed. Salvador: EDUFBA, 2000.

MENESES, J. P. La lucha libre en África. Disponível em: <http://www.soho.com.co/wf_InfoArticulo.aspx?ldArt=9437>. Acesso: 06 jan. 2009.

MORINGUE AU THÉÂTRE SOUS LES ARBRES MAI 2007. Disponível em: <http://www. youtube.com/watch? $=$ nugosGppL4w>. Acesso em: 03 jan. 2010.

MORINGUE: NOUT RACINE. Disponível em: <http://www.youtube.com/watch?v= jjK6nMsvl7Q>. Acesso em: 03 jan. 2010.

PESAVENTO, S. J. História \& história cultural. Belo Horizonte: Autêntica, 2005.

POWE, E. L. The merengé combat dance tradition of Moheli. 200 I. Disponível em: <http:// blacfoundation.org/examplepaper.pdf>. Acesso em: 18 dec. 2009.

PUNGAMARANHENSE. Disponível em: < http://www.youtube.com/watch?v=c_G9ZGFD|jM>. Acesso em: 04 jan. 2010.

REGO, W. Capoeira angola: ensaio sócio-etnográfico. Salvador: Itapuã, 1968. 
SILVA, G. O. Capoeira: do engenho a universidade. 3. ed. São Paulo: Cepeusp, 2002.

SOARES, C. E. L. A negrada instituição: os capoeiras na corte imperial - | 850- | 890. Rio de Janeiro: Access, 1999.

SOUZA, N. S. Tornar-se negro. Rio de Janeiro: Graal, 1983.

VIEIRA, L. R. A capoeira e a cultura internacional-popular. Revista Praticando Capoeira, São Paulo, n. 18, set. 2002.

VIEIRA, L. R.; ASSUNÇÃO, M. R. Mitos, controvérsias e fatos: construindo a história da capoeira. Revista de Estudos Afro-Asiáticos, Rio de Janeiro, p. 81-121, dez. 1998.

Recebido: 02 jul 2010 Aprovado: 02 fev 201 I

Endereço para correspondência: José Luiz Cirqueira Falcão Rua 20 nr. 132, apartamento 1703, Centro, Goiânia-GO CEP: 74020- 170 